\title{
P-sounder: an airborne P-band ice sounding radar
}

\section{Dall, Jørgen; Skou, Niels; Kusk, Anders; Kristensen, Steen Savstrup; Krozer, Viktor}

Published in:

IEEE International Geoscience and Remote Sensing Symposium, 2007. IGARSS 2007.

Link to article, DOI:

10.1109/IGARSS.2007.4423783

Publication date:

2007

Document Version

Publisher's PDF, also known as Version of record

Link back to DTU Orbit

Citation (APA):

Dall, J., Skou, N., Kusk, A., Kristensen, S. S., \& Krozer, V. (2007). P-sounder: an airborne P-band ice sounding radar. In IEEE International Geoscience and Remote Sensing Symposium, 2007. IGARSS 2007. IEEE. https://doi.org/10.1109/IGARSS.2007.4423783

\section{General rights}

Copyright and moral rights for the publications made accessible in the public portal are retained by the authors and/or other copyright owners and it is a condition of accessing publications that users recognise and abide by the legal requirements associated with these rights.

- Users may download and print one copy of any publication from the public portal for the purpose of private study or research.

- You may not further distribute the material or use it for any profit-making activity or commercial gain

- You may freely distribute the URL identifying the publication in the public portal 


\title{
P-sounder: an airborne P-band ice sounding radar
}

\author{
Jørgen Dall, Niels Skou, Anders Kusk, Steen Savstrup Kristensen, and Viktor Krozer \\ Danish National Space Center, Technical University of Denmark, \\ Ørsteds Plads 348, 2800 Kgs. Lyngby, Denmark, email: jd@oersted.dtu.dk
}

\begin{abstract}
This paper presents the top-level design of an airborne, P-band ice sounding radar under development at the Technical University of Denmark. The ice sounder is intended to provide more information on the electromagnetic properties of the Antarctic ice sheet at P-band. A secondary objective is to test new ice sounding techniques, e.g. polarimetry, synthetic aperture processing, and coherent clutter suppression. A system analysis involving ice scattering models confirms that it is feasible to detect the bedrock through $4 \mathrm{~km}$ of ice and to detect deep ice layers. The ice sounder design features a digital signal generator, a microstrip antenna array, a conventional RF-architecture with a central transmitter, four receivers, and internal calibration loops. In 2008 the first data acquisition campaign will take place in Greenland.
\end{abstract}

Keywords-polarimetry; clutter; sidelobes; dynamic range.

\section{INTRODUCTION}

A spaceborne, P-band ice sounding radar has been proposed as a possible Earth Explorer mission, and the system seems feasible, although the behaviour of the ice at P-band constitutes a major unknown. In order to eliminate this unknown, the European Space Agency (ESA) has assigned the Technical University of Denmark to develop an airborne Pband ice sounding radar demonstrator, the P-sounder. The development includes design, implementation, aircraft installation, and a proof-of-concept campaign over an appropriate ice sheet.

Key parameters are listed in Table 1, and additional specifications are found in [1]. The system sensitivity must be sufficient to detect the bedrock through $4 \mathrm{~km}$ of ice and to detect deep ice layers. Pulse-to-pulse coherence and full polarimetry is required. Finally, calibration and stability requirements are imposed for scientific and technical reasons.

\section{ICE SCATTERING MODELS}

Internal ice layers are due to abrupt changes of ice density, ice acidity, and ice-crystal orientation. Ice-crystal orientation fabrics are of interest because they are a product of the strain

Table 1 P-Sounder Specifications

\begin{tabular}{ll}
\hline Center frequency & $435 \mathrm{MHz}$ \\
Bandwidth (goal) & $85 \mathrm{MHz}$ \\
Polarization & quad \\
Maximum pulse length & $50 \mu \mathrm{s}$ \\
Peak power & $100-300 \mathrm{~W}$ \\
Maximum PRF & $20 \mathrm{kHz}$ \\
Operating altitude & $3500 \mathrm{~m}$ \\
\hline
\end{tabular}

The work is supported by the European Space Agency history of the ice sheet, and it seems feasible to measure the orientation, as it has previously been shown that the variation in echo strength with polarization can exceed $20 \mathrm{~dB}$ [2].

The ice layers form flat, smooth, and possibly slightly sloped isochrones, which give rise to specular reflection and a horizontal resolution determined by the diameter of the first Fresnel zone. The radar cross section (RCS) is

$$
\sigma=\pi \Gamma_{l}(0) h^{2} .
$$

$h$ is the radar altitude over the ice layer, and $\Gamma_{l}(0)$ is the Fresnel reflectivity of the ice layer at an incidence angle of $\theta=0$. Due to the air/ice interface the RCS is multiplied by a refraction gain [3] and by the square of the surface transmissivity $\left(1-\Gamma_{s}\right)^{2}$. The extinction in the ice implies another factor of

$$
a(z)=\exp \left(\int_{0}^{-z} \sigma\left(T\left(z^{\prime}\right)\right) d z^{\prime}\right)
$$

where $z$ is the ice layer depth, and the two-way extinction coefficient $\sigma$ is a function of the temperature profile $T(z)$.

The radar cross sections of the air/ice and ice/rock interfaces are computed using the Kirchhoff model presented by Picardi et al. [4]. This model has a coherent component $P_{c}$ as well as two incoherent components, $P_{n c 1}$ and $P_{n c 2}$

$$
\sigma=\pi \Gamma(\theta) h^{2} \cos ^{2} \theta\left(P_{c}+P_{n c 1}-P_{n c 2}\right) .
$$

The incoherent terms dominate for surface roughnesses in the centimetre range and above. The impact of the small-scale roughness is computed as the product of the pulse-limited footprint area and the backscatter coefficient estimated with the small perturbation model [5].

\section{SURface ClutTer}

Three types of ambiguous surface signals are superimposed the desired signal from the internal ice layers:

- clutter from the near-nadir surface overlaid through pulse sidelobes

- clutter from the surface in the along track direction

- clutter from the surface in the across track direction.

The surface signal is convolved with the compressed pulse in such a way that the strong clutter contribution from the nadir point is weighted by the distant sidelobes and added to the weak depth signal. Therefore, it is particularly important to 

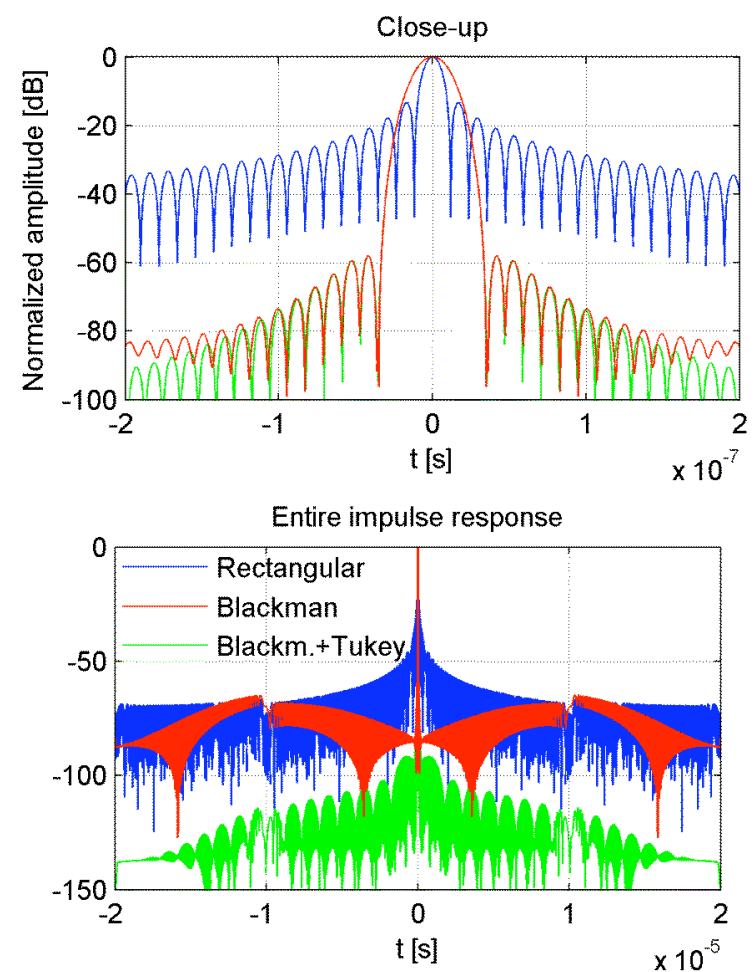

Figure 1. Normalized impulse responses for a $20 \mu$ s pulse with an $85 \mathrm{MHz}$ bandwidth. Blue: rectangular pulse and matched filter. Red: rectangular pulse and Blackman-weighted filter. Green: $2 \%$ Tukey-weighted pulse (timedomain) and Blackman-weighted filter.

suppress the distant sidelobes. While close-in sidelobes can be reduced with conventional spectral weighting, distant sidelobes can be suppressed with a slight amplitude weighting of the transmit pulse [6], e.g. with the $2 \%$ Tukey window used in Figure 1. However, such an amplitude weighting calls for a linear high-power amplifier, although the requirements can be somewhat relaxed with a pre-distortion capability as offered by the P-sounder signal generator.

The next two types of clutter are due to surface scattering from off-nadir angles, which means that the signal from an internal layer at depth $z$ is superimposed by an ambiguous surface signal from a look angle of ( $n$ is the refractive index)

$$
\theta(z)=\cos ^{-1}\left(\frac{h}{h+z n}\right) .
$$

Clutter from the along-track directions will be eliminated with Doppler processing. Clutter from the across-track directions will be suppressed by the backscattering pattern of the ice surface in combination with the antenna across-track pattern. Especially a space borne ice sounder calls for additional clutter suppression and therefore the P-sounder will feature an experimental coherent clutter suppression capability based on a multiple-phase-center antenna. The technique is similar to that of MARSIS [4], and it can be implemented with a two-channel technique or with a three-channel technique [7]

$$
\begin{aligned}
& C_{2 c h}(\theta, z)=C_{2,0}(\theta)-\alpha_{2,1}(z) \cdot C_{2,1}(\theta) \\
& C_{3 c h}(\theta, z)=C_{3,0}(\theta)-\alpha_{3,1}(z) \cdot C_{3,1}(\theta)-\alpha_{3,2}(z) \cdot C_{3,2}(\theta)
\end{aligned}
$$

The main channel signal $C_{i, 0}$ is received through an antenna with a high directivity in the nadir direction $G_{i, 0}$, while the clutter channel signals $C_{i, j}, j \neq 0$ are received through antennas having a zero in the nadir direction $G_{i, j}$. Thus the subtraction of the clutter channels leaves the nadir signal unchanged, while the scale factors $\alpha_{i, j}$ are determined such that the surface clutter is cancelled in off-nadir directions, e.g.

$$
\alpha_{2,1}(z)=\frac{G_{2,0}(\theta)}{G_{2,1}(\theta)}, \quad \theta \neq 0
$$

Here the relationship between $z$ and $\theta$ is implicit. For a surface without any across-track slope, Eq. 4 establishes this relationship, and the two techniques give the same result. However, only with the three-channel technique a potential surface slope can be estimated and the scaling factors adapted to the estimated slope.

When the two-channel technique is applied to a four-patch antenna array the intermediate channels are

$$
\begin{aligned}
& C_{2,0}=C_{A}+C_{B} \\
& C_{2,1}=C_{A}-C_{B}
\end{aligned}
$$

where $C_{A}$ is the signal from subaperture A consisting of the two middle patches, and $C_{B}$ is the signal from subaperture B, consisting of the two end patches. The three-channel technique requires access to all four patch signals.

\section{SySTEM SENSITIVITY}

A peak power of $100 \mathrm{~W}$ in combination with an antenna with four elements in the across-track direction is sufficient according to a system analysis based on the scattering models in Section II and [8], as well as the envisioned flight geometry, system parameters, and data processing. For the example defined in Table 2, Figure 2 shows the receive power contributions at the antenna port after pre-processing, pulse compression, and Doppler processing. The Parallel Doppler Processing (PDP) [9] will be employed, as it results in the same sensitivity but a better speckle reduction than Doppler beam sharpening. The surface contribution is also shown before Doppler processing. The surface and bedrock contributions are plotted versus the ambiguous depths.

The along-track pre-summing and pre-filtering will

Table 2 Ice and system parameters assumed in Figure 2

\begin{tabular}{lr}
\hline Ice depth & $4000 \mathrm{~m}$ \\
Ice temperature profile & cold \\
Large-scale roughness & $10 \mathrm{~m}$ \\
Large-scale correlation length & $100 \mathrm{~m}$ \\
Small-scale roughness & $0.02 \mathrm{~m}$ \\
Small-scale correlation length & $0.20 \mathrm{~m}$ \\
Bottom roughness & $10 \mathrm{~m}$ \\
Bottom correlation length & $100 \mathrm{~m}$ \\
\hline Altitude above ice surface & $750 \mathrm{~m}$ \\
Signal bandwidth & $85 \mathrm{MHz}$ \\
Sampling frequency & $249 \mathrm{MHz}$ \\
Effective PRF & $5.5 \mathrm{kHz}$ \\
Pulse length & $5 \mu \mathrm{s}$ \\
Peak power & $100 \mathrm{~W}$ \\
Effective ADC bits & 11 \\
\hline
\end{tabular}




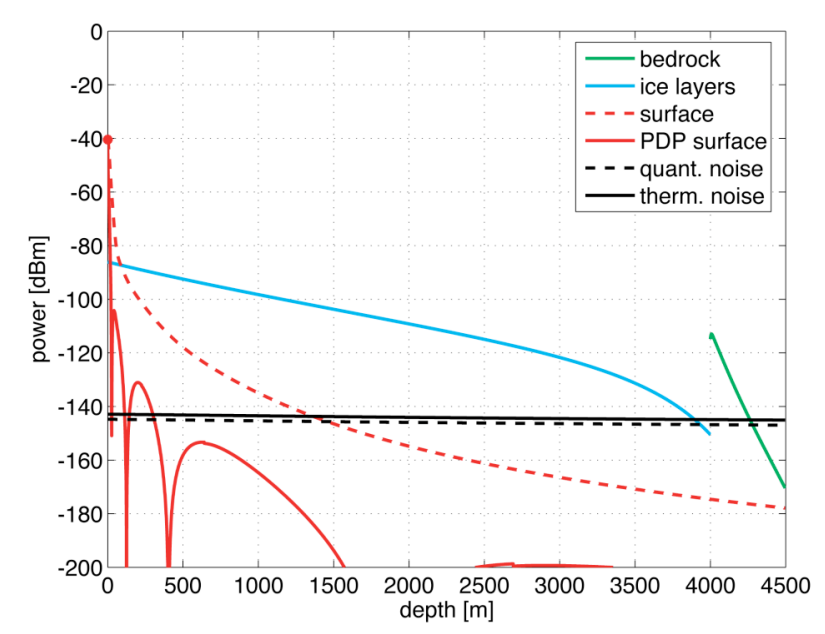

Figure 2. Receive power estimated for the example in Table 2.

improve the signal-to-noise ratio (SNR) and reduce the effective pulse repetition frequency (PRF). Hence, it will be carried out on-board. Although the pulse decimation factor may exceed 500, the filter bandwidth will be large enough that surface slopes, aircraft maneuvering, and range migration can be neglected in the on-board pre-processing.

Figure 2 shows that the bedrock can easily be detected, even at a depth of $4 \mathrm{~km}$. Near the bedrock the higher ice temperature makes the ice layer curve drop below the noise curves. The surface clutter does not mask the bedrock signal, but the ice layers are masked down to a depth of about $15 \mathrm{~m}$ if PDP is applied. A crystal orientation fabric is assumed, but layers caused by density differences in the upper few tens of meters have a larger reflectivity than those associated with crystal orientation [7] and would therefore be masked to a smaller depth. Mapping layers in the uppermost $25 \mathrm{~m}$ of the ice sheet is not strictly required to meet the scientific goals [10].

\section{DYNAMIC RANGE}

Detecting the bedrock under a $4 \mathrm{~km}$ thick ice sheet requires a system with a dynamic range on the order of $100 \mathrm{~dB}$. A/Dconverters with such a dynamic range (17 bits are required) do not have the required bandwidth, and reducing the dynamic range of the receive signal by means of sensitivity time control (STC) might jeopardize the sidelobe suppression, even after inverse STC. Instead, a shallow / deep sounding approach is adopted, i.e. overlapped near-surface and near-bottom windows are sounded separately, when necessary. This can be done simultaneously by alternating the system gain on a pulseto-pulse basis, but it costs $3 \mathrm{~dB}$ on the SNR, as the effective PRF is halved.

The shallow / deep sounding mode of operation improves the dynamic range and it enables short and long pulses to be used for shallow and deep sounding, respectively, thereby reducing the risk that near-surface ice layers are masked by surface clutter in combination with range sidelobes.

Figure 3 shows the contributions to the raw signal, i.e. the single-pulse signal that has neither been pre-processed nor pulse compressed. All signals are referenced to the antenna
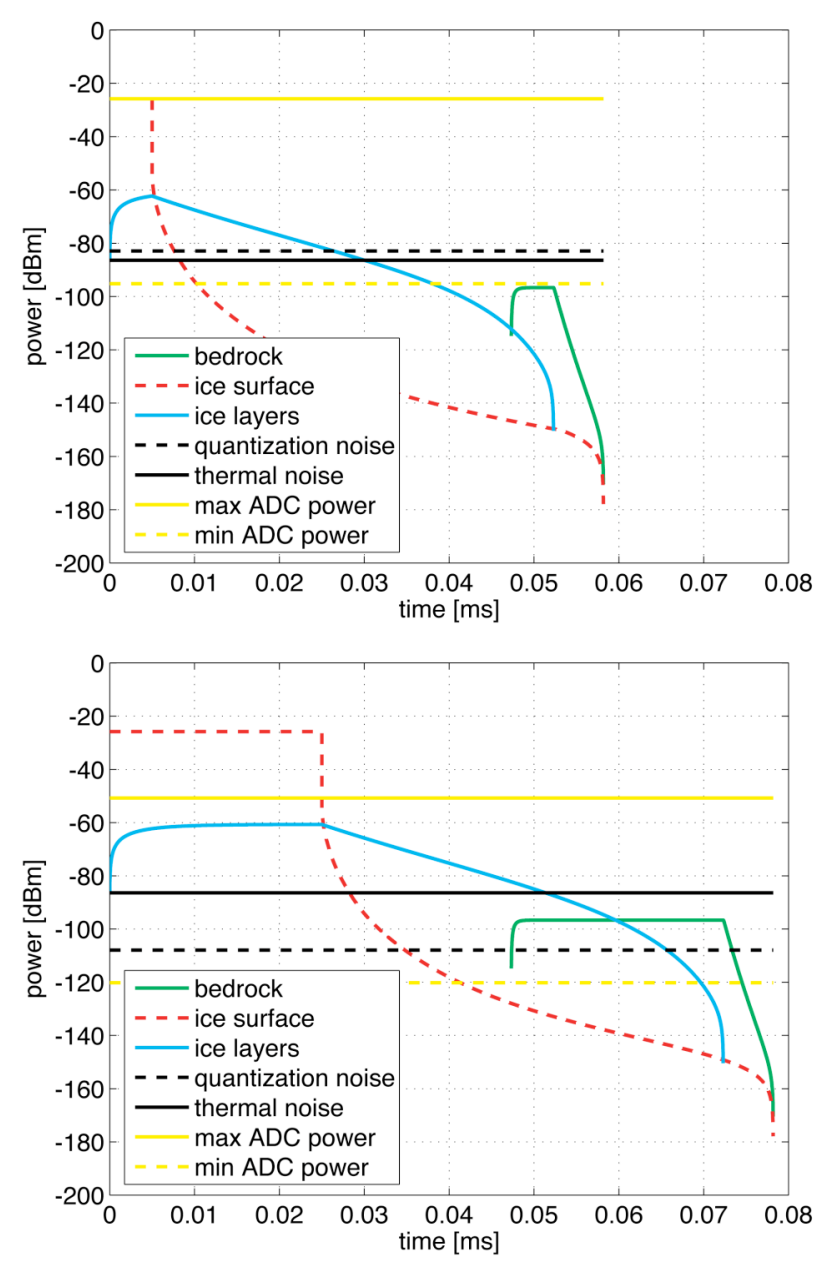

Figure 3. Shallow / deep sounding. The raw signals are based on the parameters in Table 2, except that the ice surface roughness is $1 \mathrm{~m}$ (worst case). Top: shallow sounding with reduced receiver gain. Bottom: deep sounding with blanked surface return and a pulse length increased to $25 \mu \mathrm{s}$.

port and plotted as a function of time, as there is no one-to-one correspondence between time and range for raw signals encoded with a long transmit pulse.

\section{IMPLEMENTATION}

The P-sounder will to a large extent, be based on commercial-off-the-shelf (COTS) modules. In practice, the modules range from real COTS over "in-house-off-the-shelf" units to purpose-built units, as several modules are not commercially available with the required specifications. The "in-house-off-the-shelf" units have previously been developed for other remote sensing sensors. Some of these units will be directly incorporated in the P-sounder, e.g. the digital signal generator (DSG), while others will be reproduced after some redesign, e.g. the digital front end (DFE).

A highly reconfigurable system is obtained with the architecture shown in Figure 4. Polarimetry is implemented with polarization switches (SW3) on the transmit side and dedicated channels for horizontal and vertical polarization on the receive side. Any polarization (including the mandatory circular polarization) can be synthesized from the quad, linear polarized signal. 


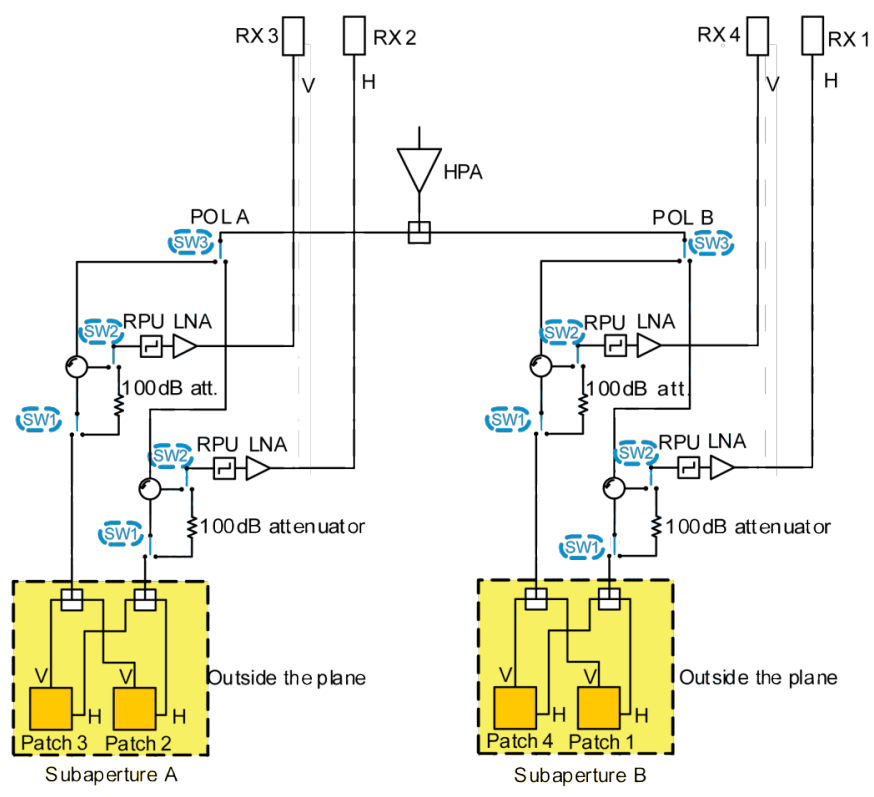

Figure 4. P-sounder RF-Subsystem and antenna. The two end elements (patch 1 and 4) are placed next to one another to simply the diagram.

Clutter suppression with the two-channel multiple-phase center technique is enabled with the four receiver channels acquiring polarimetric signals from the two sub-apertures separately. In single-aperture mode, the four-channel DFE coherently adds the sub-aperture signals. Three-channel clutter suppression calls for re-cabling such that the four receiver channels directly connect to the four $\mathrm{V}$ ports (or $\mathrm{H}$ ports) of the antenna elements. Also, the two polarization switches (SW3) have to be replaced by two power dividers in order to transmit on all four antenna elements simultaneously. Thus, polarimetry is not supported in this mode, and in-flight re-configuration is not possible.

Time-multiplexed shallow / deep sounding requires gain to be switched in and out of the signal path at some point. The best SNR is obtained by adjusting the receiver gain after the LNA. When referenced to the antenna ports, the quantization noise and the maximum ADC power depend on this receiver gain, which can be adapted to shallow and deep sounding as shown in Figure 3.

Based on very good experience with the airborne EMISAR system [11], the internal calibration is carried out with the same signal as used during normal operation and with a signal path that differs only with respect to stable, passive units like the antenna, which can be characterized prior to the flight.

A conservative design with a central transmitter and receiver unit mounted inside the aircraft plus a passive antenna mounted outside, has been preferred over a more advanced distributed system with transmit and receive modules directly behind the antenna elements. One reason is system calibration and stability. Another reason is aircraft installation costs.

A layout with a single transmitter simplifies the internal calibration procedure as the number of transmit / receive combinations is greatly reduced. Also, it enables the active components to be installed inside the aircraft in a thermally controlled environment. This is important, as calibration must take place immediately before and after every data acquisition, relying on the system to be stable in between.

A Twin Otter has been selected for the P-sounder. This aircraft meets the requirements to altitude, range etc., and it excels by a short take-off and landing (STOL) capability, a stable flight, and relatively low installation, certification, and operation costs. Several Twin Otter operators are based in arctic regions or have experience flying in artic regions. A Twin Otter operated by Air Greenland already has an antenna installation (for ASIRAS [12]) quite similar to that of the Psounder. Using a light, passive antenna it is likely that the hard-points can be re-used and the certification is facilitated.

\section{CONCLUSION}

The P-sounder is a polarimetric ice sounding radar that has been designed to suppress the surface clutter in a number of ways and to have a very large dynamic range.

The system analysis and the system design have been completed, and the implementation is now in progress. By the end of April 2007 the antenna elements, the digital signal generator, most of the RF subsystem and the control hardware has been implemented. The implementation of the digital front end hardware and software is about to be completed. The first data acquisition campaign is planned to take place in Greenland in 2008.

\section{REFERENCES}

[1] "Annex 1 to P-Band Ice Sounding Radar Demonstrator Development; Technical Specifications”, ESTEC TEC-ETP/2004.31, version 2, November 2004.

[2] B.M.E Smith and S. Evans, "Radio Echo Sounding: Absorption and scattering by water inclusions and ice lenses", Journal of Glaciology, Vol. 11, No. 61, pp. 133-145, 1974.

[3] J.R. Wait, (ed), "Electromagnetic Probing in Geophysics", The Golem Press, Boulder Colorado, 1971.

[4] G. Picardi, D. Biccari, R. Seu, L. Marinangeli, W.T.K. Johnson, R.L. Jordan, J. Plaut, A. Safaenili, D.A. Gurnett, G.G. Ori, R. Orosei, D. Calabrese, E. Zampolini, "Performance and surface scattering models for the Mars Advanced Radar for Subsurface and Ionosphere Sounding (MARSIS)", Planetary and Space Science, Elsevier, No. 52, 2004.

[5] F.T. Ulaby, R.K. Moore, A.K. Fung, "Microwave Remote Sensing: Active and Passive", Vol. II, Addison-Wesley, London, 1982.

[6] T.X. Misaridis and J.A. Jensen, "An effective coded excitation scheme based on a predistorted FM signal and an optimized digitial filter", Proc. of IEEE International Ultrasonics Symposium, pp. 1589-1593, 1999.

[7] B.R. Velado, "Radio Echo Sounding of Antarctica Using a Spaceborne P-band radar", ESTEC Working Paper No. 2243.

[8] "Annex 2 to P-Band Ice Sounding Radar Demonstrator Development, A simplified scattering model", ESTEC TEC-ETP/2004.31, version 2, November 2004.

[9] R.K. Raney, B.L. Gotwols, and J.R. Jensen, "Optimal Processing of Radar Ice Sounding Data”, Proc. of IGARSS’99, pp. 92-94, 1999.

[10] B. Rommen, Personal communication, System Analysis and Requirements review, ESTEC, July 4, 2006.

[11] E. Lintz Christensen, N. Skou, J. Dall, K.W. Woelders, J.H. Jørgensen, J. Granholm, S.N. Madsen, "EMISAR: An Absolutely Calibrated Polarimetric L- and C-band SAR", IEEE Transactions on Geoscience and Remote Sensing, Vol. 36, No. 6, pp. 1852-1865, Nov. 1998.

[12] R. Cullen, M.W.J. Davidson, M.R. Drinkwater, .R. Francis, C. Hass, R.L. Hawley, C.M. Mavrocordatos, E.M. Morris, W. Rack, G. Ratier, P. Viau, and D.J. Wingham, "ESA's New Range of radar altimeters for the extraction of geophysical parameters from land, sea ice and ocean surfaces", 15 Years of progress in Radar Altimetry Symposium, Venice, March, 2006. 